ОСОБЕННОСТИ ОРГАНИЗАЦИИ АМБУЛАТОРНО-ПОЛИКЛИНИЧЕСКОЙ ПОМОЩИ ВЗРОСЛОМУ И ДЕТСКОМУ НАСЕЛЕНИЮ НА БАЗЕ МЕДИЦИНСКОГО ЦЕНТРА Г.ЯКУТСКА РЕСПУБЛИКИ САХА (ЯКУТИЯ)

(C) Е.А. Борисова ${ }^{1}$, И.П. Луцкан ${ }^{1}$, Н.В. Саввина ${ }^{1}$, Л.Ф. Тимофеев ${ }^{1}$, О.Е. Коновалов ${ }^{2,3}$

Северо-Восточный федеральный университет имени М.К. Аммосова, Якутск, Российская Федерация (1)

Национальный научно-исследовательский институт общественного здоровья имени Н.А. Семашко, Москва, Российская Федерация (2)

Российский университет Дружбы народов, Москва, Российская Федерация (3)

Цель. Изучение организации амбулаторно-поликлинической помощи в г. Якутске, в том числе на базе Медицинского центра г. Якутска в период с 2012 по 2018 гг.

Материалы и методы. Для настоящего исследования в работе были использованы статистические данные о кадровом обеспечении, посещаемости, заболеваемости детского и взрослого населения города Якутска по классам МКБ-10 (на 100 тыс. населения) за 2012-2018 гг., полученные из официального источника - Якутского республиканского медицинского информационно-аналитического центра и медицинских организаций, оказывающих первичную медико-санитарную помощь. Были проанализированы данные официальных статистических отчетов (формы 7, 12, 17, 30, 36), демографические показатели населения города Якутска. Статистическую обработку данных проводили с использованием программного обеспечения Statistica10 (Stat Soft Inc., США) и Microsoft Excel. Выполнен SWOT-анализ организации амбулаторно-поликлинической помощи населению города Якутска.

Результаты. Состояние здоровья населения г. Якутска характеризовалось высоким уровнем заболеваемости всех возрастных групп населения, организация медицинской помощи населению г. Якутска - расширением сети медицинских организаций и укреплением их материально-технической базы. Введение новых механизмов управления в деятельность Медицинского центра г. Якутска в 2012-2018 гг. позволило добиться высоких результатов работы среди прикрепленного населения.

Выводы. Разработка стандартов качества лечебно-диагностических услуг привела к снижению количества актов страховых компаний с дефектами оказания медицинской помощи и штрафными санкциями. Введение «эффективного контракта» позволило увеличить прежний уровень заработной платы медицинских работников, дополнительно привлечь новых работников, а также повысить эффективность деятельности организации. Формирование в медицинской организации системы многоуровневого аудита эффективности на основе процессного подхода помогло определить сильные и слабые места организации и разработать мероприятия по повышению доступности и качества медицинской помощи.

Ключевые слова: амбулаторно-поликлиническая помощь; качество медищинской помощи; первичное звено здравоохранения; пациентоориентированность; доступность медицинской помощии. 


\title{
PECULIARITIES OF ORGANIZATION OF OUTPATIENT CARE FOR ADULTS AND CHILDREN ON BASE OF MEDICAL CENTER OF YAKUTSK CITY OF THE REPUBLIC OF SAKHA (YAKUTIA)
}

\author{
E.A. Borisova ${ }^{1}$, I.P. Lutskan ${ }^{1}$, N.V. Savvina ${ }^{1}$, L.F. Timofeev ${ }^{1}$, O.E. Konovalov ${ }^{2,3}$
}

Ammosov North-East Federal University, Yakutsk, Russian Federation (1)

Semashko National Research Institute of Public Health, Moscow, Russian Federation (2)

Peoples' Friendship University of Russia, Moscow, Russian Federation (3)

Aim. To study organization of the outpatient care in Yakutsk, incl. that on the base of Medical Center of Yakutsk in the period from 2012 to 2018.

Materials and Methods. For this study, statistical data were used on staffing, attendance, morbidity of the children's and adult population of the city of Yakutsk by ICD-10 classes (per 100 thousand population) for 2012-2018. Statistical data for the work were obtained from an official source - Yakutsk Republican Medical Information and Analytical Center and medical organizations providing primary health care. The work used the data of official statistical reports (forms 7, 12, 17, 30, 36), demographic parameters of the population of the city of Yakutsk. Statistical data processing was carried out using Statistica10 software (Stat Soft Inc., USA) and Microsoft Excel. SWOT analysis of the organization of outpatient care for the population of the city of Yakutsk was carried out.

Results. The health status of the population of Yakutsk was characterized by a high level of morbidity in all age groups. Organization of medical care for the population of Yakutsk was characterized by expansion of the network of medical organizations and strengthening of their material and technical base. Introduction of new management mechanisms into the activities of Medical Center in Yakutsk in 2012-2018 allowed to achieve high results of work among the attached population.

Conclusions. Development of quality standards for medical and diagnostic services has reduced the number of acts of insurance companies with defects in the provision of medical care and penalties. Introduction of an «effective contract» made it possible to increase the previous level of salaries of medical workers, to additionally attract new workers, and also to increase the efficiency of the organization. Formation in a medical organization of a multilevel performance audit system based on a process approach made it possible to identify the strengths and weaknesses of the organization and develop measures to improve the availability and quality of medical care.

Keywords: outpatient care; quality of medical care; primary health care; patient orientation; availability of medical care.

Амбулаторно-поликлиническая помощь является наиболее массовым видом медицинской помощи населению, ее основой является первичная медико-санитарная помощь - один из самых доступных, при этом по экономическим и социальным параметрам приемлемый вид медицинской помощи. В то же время, по мнению ряда авторов, реформа организаций, которые оказывают амбулаторно-поликлиническую по- мощь населению, являясь основным элементом структурных преобразований в здравоохранении, не определилась в своих основных направлениях и не набрала необходимые темпы проведения реальных преобразований [1-3]. Так, к несовершенству организации деятельности амбулаторно-поликлинического звена медицинских учреждений следует отнести: отсутствие четкого научного обоснования преобразования амбу- 
латорно-поликлинической помощи; заторможенные темпы осуществления реформы системы здравоохранения в направлении формирования участков общей врачебной практики; низкая управленческая подготовленность руководителей вышеуказанных учреждений; слабая конкурентоспособность на рынке медицинских услуг; отставание в развитии системы информационного обеспечения деятельности и др. [2,4].

Данные проблемы имеют место и в организации амбулаторно-поликлинической помощи населению в Якутии, в том числе и в условиях городского округа «г. Якутск», что и явилось основанием для проведения настоящего исследования.

Цель - изучение организации амбулаторно-поликлинической помощи в г. Якутске, в том числе на базе Медицинского центра г. Якутска в период с 2012 по 2018 гг.

\section{Материалы и методы}

Для настоящего исследования в работе были использованы статистические данные о кадровом обеспечении, посещаемости, заболеваемости детского и взрослого населения города Якутска по классам МКБ-10 (на 100 тыс. населения) за 2012-2018 гг., полученные из официального источника - Якутского республиканского медицинского информационно-аналитического центра, а также Территориального органа (Сахастат) Федеральной службы государственной статистики по Республике Саха (Якутия) и медицинских организаций, оказывающих первичную медико-санитарную помощь г. Якутска. Проанализированы данные официальных статистических отчетов (формы 7, $12,17,30,36)$, демографические показатели населения города Якутска. Применялись: статистический, аналитический методы исследования и организационный эксперимент. Статистическая обработка данных проводилась с использованием программного обеспечения Statistica 10 (Stat Soft Inc., США) и Microsoft Excel. Выполнен SWOTанализ организации амбулаторно-поликлинической помощи населению города Якутска. Для достижения поставленной цели работы использованы данные медицинской информационной системы Trastmed.

\section{Результаты и их обсуждение}

Медико-демографические данные по городскому округу «г. Якутск» за 20102018 гг. свидетельствуют о росте численности населения за счет естественного прироста, внутренней и внешней миграции на 16,2\%. На 01.01.2018 в структуре населения удельный вес взрослых составил $72,6 \%$, подростков - 3,4\%, детей до 14 лет - 23,8\%. В структуре населения на $19,1 \%$ выросла численность детей до 14 лет, на $16,4 \%$ - взрослых, на 44,3\% выросла численность населения в трудоспособном возрасте. В указанный период времени сформировался устойчивый тренд роста ожидаемой продолжительности жизни населения. Средний возраст жителя г. Якутска составляет 32,2 года. В гендерной структуре населения преобладают женщины - 52,8\%. Женщины фертильного возраста составляют 56\%. Состояние здоровья населения г. Якутска характеризуется высоким уровнем заболеваемости всех возрастных групп населения. В изучаемый период существенно выросла заболеваемость злокачественными новообразованиями, продолжает сохраняться неблагополучная эпидемиологическая ситуация по туберкулезу, алкоголизму, наркомании и токсикомании. В структуре смертности преобладают болезни системы кровообращения. Причинами тому является низкая приверженность населения к ведению здорового образа жизни, а также сохраняющиеся проблемы в организации медицинской помощи жителям г. Якутска и республики.

Надо отметить, что организация медицинской помощи населению г. Якутска характеризовалась расширением сети медицинских организаций и укреплением их материально-технической базы. Быстрыми темпами проводится информатизация здравоохранения. В медицинских организациях г. Якутска была внедрена система записи к врачу электронно, для этого используются портал пациента er14.ru, единый Call-центр, инфоматы, мобильные приложения «Облачная поликлиника», «Телемед» или сай- 
ты медучреждений и др. Активно проводятся мероприятия по формированию здорового образа жизни и др. [5-7].

В здравоохранении города Якутска в 2010-2012 гг. сформировались организационно-экономические риски, вызванные устаревшей организационной структурой, снижением доходности медицинских организаций, неэффективным использованием ресурсов, слабой управленческой подготовкой руководителей медицинских организаций, снижением качества и доступности медицинской помощи населению и др. Перевод амбулаторно-поликлинических учреждений на «подушевое» финансирование создало дополнительные финансовые риски, вплоть до банкротства фондодержателя (медицинской организации). Реструктуризация городского здравоохранения в 2012 г. путем слияния ряда медицинских организаций, оказывающих амбулаторно-поликлиническую помощь, позволила привести в соответствие численность, структуру и показатели здоровья жителей г. Якутска (спрос на медицинские услуги) с организационной структурой медицинских организаций (предложение медицинских услуг), повысить эффективность и уменьшить издержки на управление, более эффективно использовать ресурсы медицинских организаций, повысить доступность и качество медицинской помощи.

SWOT-анализ позволил выявить разные стороны организации амбулаторнополиклинической помощи населению г. Якутска (табл. 1).

Предпосылками совершенствования амбулаторно-поликлинической помощи жителям г. Якутска явились, с одной стороны, высокий уровень заболеваемости во всех возрастных групп населения, преждевременной смертности и инвалидизации населения, высокая распространенность поведенческих факторов риска неинфекционных заболеваний, низкая приверженность населения к соблюдению здорового образа жизни, а также наличие в системе амбулаторно-поликлинической помощи организационно-экономических рисков, негативно влияющих на эффективность использования ресурсов и обеспечение доступной и качественной амбулаторно-поликлинической помощи, а, с другой стороны, недостаточная организация амбулаторно-поликлинической помощи населению в части нормативного правового и ресурсного обеспечения $[6,7]$. Основными направлениями совершенствования организации амбулаторно-поликлинической помощи населению городского округа «г. Якутск» явились:

- реализация здоровье-сберегающих технологии (программ по обучению грамотной заботе о своем здоровье и формированию культуры здоровья учащихся школ, ССУЗов и ВУЗОВ, мотивации их к ведению здорового образа жизни, предупреждению вредных привычек, предусматривающие также проведение организационно-воспитательной работы со школьниками после уроков, просвещение их родителей, контроль и помощь в обеспечении надлежащих гигиенических условий в соответствии с регламентациями СанПиНов, способствующих предотвращению состояния переутомления, гиподинамии и других дезаптационных состояний);

- формирование трехуровневой организационной структуры амбулаторно-поликлинической помощи населению с учетом уровней, видов, условий и форм оказания медицинской помощи в соответствии с федеральным и региональным законодательством;

- информатизация системы амбулаторно-поликлинической помощи населению;

- выстраивание вертикальной системы управления качеством медицинской помощи, разработка и внедрение системы стандартов качества и безопасности медицинской деятельности на основе процессного подхода;

- охрана материнства и детства;

- разработка научного обоснования и реализация плана мероприятий по совершенствованию организации амбулаторнополиклинической помощи населению городского округа «г. Якутск» с учетом сети медицинских организаций, их ресурсного, технологического и нормативного правового обеспечения. 
Таблица 1

\section{SWOT-анализ амбулаторно-поликлинической помощц населению г. Якутска}

\begin{tabular}{|c|c|}
\hline Сильные стороныл (S) & Слабые стороны (W) \\
\hline $\begin{array}{l}\text { 1. Наличие в регионе собственной учебной базы в } \\
\text { виде медицинского института Северо-Восточного } \\
\text { федерального университета имени М.К. Аммо- } \\
\text { сова и Якутского медицинского колледжа. }\end{array}$ & $\begin{array}{l}\text { 1. Недостаточно разветвлённая сеть медицинских } \\
\text { организаций, их структурных подразделений, ока- } \\
\text { зывающих амбулаторно-поликлиническую по- } \\
\text { мощь, дефицит площадей. }\end{array}$ \\
\hline $\begin{array}{l}\text { 2. Развития транспортная инфраструктура города } \\
\text { Якутска и его пригородов. }\end{array}$ & $\begin{array}{l}\text { 2. Слабая материально-техническая база медицин- } \\
\text { ских организаций, несоответствие табелям осна- } \\
\text { щения, высокий уровень износа медицинского обо- } \\
\text { рудования - до } 70-80 \% \text {. }\end{array}$ \\
\hline 3. $\operatorname{Cox}$ & $\begin{array}{l}\text { 3. Отсутствие корреляции между структурой забо- } \\
\text { леваемости и смертности населения и государ- } \\
\text { ственным заданием по его объемам и структуре. }\end{array}$ \\
\hline $\begin{array}{l}\text { 4. Сложившаяся система научно-практического } \\
\text { взаимодействия. }\end{array}$ & $\begin{array}{l}\text { 4. Необходимость приведения численности меди- } \\
\text { цинских кадров к нормативным показателям. }\end{array}$ \\
\hline $\begin{array}{l}\text { 5.Относительно высокий профессиональный уро- } \\
\text { вень медицинских работников. }\end{array}$ & $\begin{array}{l}\text { 5. Отсутствие инструментов оценки эффективно- } \\
\text { сти деятельности медицинских организаций, ок-- } \\
\text { зывающих амбулаторно-поликлиническую по- } \\
\text { мощь. }\end{array}$ \\
\hline $\begin{array}{l}\text { 6. Реализация приоритетного национального про- } \\
\text { екта «Здоровье». }\end{array}$ & $\begin{array}{l}\text { 6. Низкая удовлетворенность потребителей полу- } \\
\text { чаемой медицинской помощью по данным социо- } \\
\text { логических опросов. }\end{array}$ \\
\hline $\begin{array}{l}\text { 7. Сформированная система поддержки отрасли за } \\
\text { счет федерального, краевого и муниципального } \\
\text { бюджетов в рамках действующих целевых про- } \\
\text { грамм. }\end{array}$ & $\begin{array}{l}\text { 7. Недостаточный уровень информационного об- } \\
\text { мена и развитие электронного документооборота в } \\
\text { медицинских организациях, оказывающих амбула- } \\
\text { торно-поликлиническую помощь. }\end{array}$ \\
\hline & \\
\hline $\begin{array}{l}\text { 1. Формирование эффективной государственной } \\
\text { региональной политики в области здравоохране- } \\
\text { ния. }\end{array}$ & $\begin{array}{l}\text { 1. Дефицит медицинских кадров, особенно среди } \\
\text { узких специалистов амбулаторного звена, их по- } \\
\text { старение, отток медицинского персонала в негосу- } \\
\text { дарственный сектор. Высокий уровень совмести- } \\
\text { тельства. Высокая интенсивность труда. }\end{array}$ \\
\hline $\begin{array}{l}\text { 2. Создание крупных медицинских объединений } \\
\text { как инструмента повышения доступности и каче- } \\
\text { ства медицинской помощи и более эффективного } \\
\text { использования ресурсов. }\end{array}$ & $\begin{array}{l}\text { 2. Большая загруженность врачей ведением боль- } \\
\text { шого количества обязательной медицинской доку- } \\
\text { ментации, неудовлетворительное ведение меди- } \\
\text { цинской документации - до } 54 \% \text {. }\end{array}$ \\
\hline $\begin{array}{l}\text { 3.Разработка привлекательных инвестиционных } \\
\text { проектов в форме государственно-частного парт- } \\
\text { нерства (ГЧП) }\end{array}$ & $\begin{array}{l}\text { 3. Дефицит квалифицированных управленцев в } \\
\text { здравоохранении, недостаточная ответственность } \\
\text { руководителей здравоохранения всех уровней за } \\
\text { результаты труда. }\end{array}$ \\
\hline $\begin{array}{l}\text { 4. Развитие информационно-коммуникативных } \\
\text { технологий. }\end{array}$ & $\begin{array}{l}\text { 4. Несоответствие нормативных объемов медицин- } \\
\text { ской помощи по Программе государственных га- } \\
\text { рантий реальным потребностям населения. }\end{array}$ \\
\hline $\begin{array}{l}\text { 5. Создание совместно с Министерством и соци- } \\
\text { альной защиты сети хосписов для оказания палли- } \\
\text { ативной помощи. }\end{array}$ & $\begin{array}{l}\text { 5. Возникновение финансовых рисков при пере- } \\
\text { ходе на новые механизмы финансирования меди- } \\
\text { цинских организаций, которые могут привести к } \\
\text { банкротству фондодержателя. }\end{array}$ \\
\hline 6. $\mathrm{O}$ & \\
\hline
\end{tabular}

Реформирование сети медицинских организаций г. Якутска путем их реструктуризации, через объединение трех учреждений и создания Медицинского центра г. Якутска, возникновение новых струк- турных подразделений, в частности Центр поддержки и сопровождения пациентов, Центр охраны здоровья семьи и репродукции, централизованная лаборатория и др., внедрение многоуровневой модели оказа- 
ния медицинской помощи, привлечение и закрепление новых кадров, значительное усиление материально-технической базы, позволило в ограниченные сроки возместить неравномерность развития амбулаторно-поликлинической помощи, повысить финансирование медицинской организации, в том числе технологическое и ресурсное обеспечение, обеспечить на более высоком уровне доступность и качество медицинской помощи для прикрепленного населения [5-7]. Введение «эффективного контракта» позволило не только сохранить, но и увеличить прежний уровень заработной платы медицинских работников, дополнительно привлечь новых работников, а также повысить эффективность деятельности организации.

Введение указанных механизмов в деятельность Медицинского центра г. Якутска в 2013-2018 гг. позволило добиться следующих результатов работы среди прикрепленного населения:

- повысились демографические показатели: показатель общей смертности уменьшился в 2 раза - с 7,18 до 3,57 случаев на 1000 нас., в свою очередь показатель рождаемости увеличился в 1,1 раза - с 16,5 до 18,3 случаев на 1000 нас., естественный прирост населения увеличился в 1,63 разас 9,24 до 14,75 случаев на 1000 населения;

- смертность населения от болезней системы кровообращения оказалась значительно ниже целевого значения (факт - 260,1 случая на 100 тыс. населения, пороговое значение - 420,0 случаев), от злокачественных новообразований (соответственно - 113,2 и 125,4$)$, от туберкулеза $(1,14$ и 8,76$)$;

- уменьшился показатель младенческой смертности (с 8,93 до 3,84 случаев на 1000 родившихся живыми);

- увеличилась численность прикрепленного населения с 86,2 тыс. человек в 2013 г. до 90,1 тыс. человек на конец 2018 г. [5];

- увеличилось на 2,5\% число посещений к врачам поликлинических отделений, в т.ч. с профилактической целью на $42 \%$, а число посещений на дому - на $28 \%$;
- Медицинский центр г. Якутска ежегодно выполняет плановые объемы медицинской помощи; при сохранении объёмов финансирования медицинской организации из различных источников;

- были достигнуты целевые показатели увеличения оплаты труда для врачей, среднего и младшего медицинского персонала в соответствии с дорожной картой;

- была улучшена материально-техническая база медицинской организации - в период с 01.01.2013 по 01.01.2018 показатель фондооснащенности вырос на 9,3\%, а фондовооруженности - на 9,2\%;

- были использованы в рамках организационного эксперимента новые формы обслуживания прикрепленного населения (создание офиса врачебной практики вне медицинской организации, дистанционное консультирование врачом-гериатром, выездное обслуживание лиц пожилого возраста социальными бригадами (соцработник, врач, представитель местной администрации);

- удовлетворенность пациентов качеством и доступностью медицинской помощи выросла с 58,59 до 71,25\%, и др.

Важное место в проблеме повышения эффективности деятельности медицинских организаций занимает внутренний контроль качества и безопасности медицинской деятельности. Разработанное в МЦЯ Положение о системе менеджмента качества, на основании ISO 9001-2015 в части планирования, обеспечения и улучшения качества и безопасности медицинской деятельности [7]. Выделение процессов и подпроцессов, стандартизация медицинской помощи позволяют создать механизм внутреннего контроля безопасности и качества медицинской деятельности в медицинской организации. Инструментами такого управления могут явиться стандарты качества лечебно-диагностических услуг в учреждении амбулаторнополиклинического типа на основе стандартизации структурных подразделений и сквозного процессного подхода.

Разработка стандартов качества лечебно-диагностических услуг позволило снизить количество штрафных санкций и 
актов с дефектами со стороны страховых компаний. При проведении экспертизы качества медицинской помощи Государственной страховой медицинской компанией «Сахамедстрах» было установлено снижение нарушений по амбулаторно-поликлинической помощи с 27,8 до 7,8\%, снижение нарушений по стационарной помощи с 28,4 до 3,46\%; по линии экспертиз, организованных ООО «Росгосстрах Медицина» было также установлено снижение нарушений соответственно до 2,4 и 4,7\%.

Формирование в медицинской организации системы многоуровневого аудита эффективности на основе процессного подхода позволяет определить сильные и слабые места организации и разработать мероприятия по повышению доступности и качества медицинской помощи. Порядок проведения внутренних аудитов системы менеджмента качества в Медицинском центре г. Якутска определен локальным нормативным актом «Регламент процесса проведения внутренних аудитов».

\section{Выводы}

1. Разработка стандартов качества лечебно-диагностических услуг привела к снижению количества замечаний со стороны страховых компаний.

2. Введение «эффективного контракта» позволило увеличить прежний уровень заработной платы медицинских работников, дополнительно привлечь новых работников, а также повысить эффективность деятельности организации.

3. Формирование в медицинской организации системы многоуровневого аудита эффективности на основе процессного подхода помогает определить сильные и слабые места организации и разработать мероприятия по повышению доступности и качества медицинской помощи.

Таким образом, проводимые системные мероприятия в части совершенствования организации амбулаторно-поликлинической помощи населению Республики Саха (Якутия) на примере городского округа «г. Якутск» позволили повысить доступность, качество и безопасность медицинской деятельности.

\section{Дополнительная информация}

Конфликт интересов. Авторы декларируют отсутствие явных и потенциальных конфликтов интересов, о которых необходимо сообщить в связи с публикацией данной статьи.

Этика. В исследовании использованы данные людей в соответствии с подписанным информированным согласием.

Финансирование. Исследование не имело спонсорской поддержки.

\section{Участие авторов:}

Концепция и дизайн исследования, интерпретация результатов - Луцкан И.П., Саввина Н.В., Тимофеев Л.Ф., Коновалов О.Е.

Получение данных (непосредственное выполнение экспериментов, исследований), анализ данных - Луцкан И.П., Борисова Е.А., Тимофеев А.Л.

Написание статьи - Луцкан И.П.

Утверждение рукописи для публикации Саввина Н.В., Тимофеев Л.Ф., Коновалов О.Е.

\section{Литература}

1. Закирова А.Ш., Ахметзянова Г.З., Альмухаметов А.А. Использование «бережливых технологий» в оказании амбулаторно-поликлинической помощи. В сб.: Первичная медико-санитарная помощь. Опыт передовых практик в рамках реализации национального проекта «Здравоохранение»: сборник материалов Республиканской научно-практической конференции; 6 декабря 2019 г.; Казань. Казань: Изд-во КГМУ; 2019. С. 55-57.

2. Гурьянова В.А., Риккер Д.Д., Шубин Л.Л. Состояние амбулаторно-поликлинической помощи населению в Удмуртской Республике в 2013 году // Синергия Наук. 2019. №41. С. 233-241.

3. Руина О.В., Земскова С.Е., Лузина Е.А., и др. Изменения в работе амбулаторно-поликлини- ческого звена; что нового? Нерешенные вопросы. В сб.: Медицинский работник года 2019: сборник статей Международного научноисследовательского конкурса; 25 декабря 2019 г.; Петрозаводск. Казань; 2019. С. 6-16.

4. Москвина С., Черепанова Н. Как решить проблему дефицита медперсонала. Опыт практиков // Главная медицинская сестра. 2020. №4. С. 48-51.

5. Борисова Е.А. Организация амбулаторно-поликлинической помощи населению городского округа «город Якутск» // Дальневосточный медицинский журнал. 2018. №3. С. 50-53.

6. Борисова Е.А., Савина Н.В., Луцкан И.П., и др. Новые эффективные подходы в оплате труда медицинских работников // Вестник Российского университета дружбы народов. Серия: Меди- 
цина. 2015. №1. С. 12-21.

7. Борисова Е.А., Саввина Н.В., Луцкан И.П., и др. Внедрение «эффективного контракта» на примере медицинского центра г. Якутска // Проблемы социальной гигиены, здравоохранения и истории медицины. 2015. Т. 23, №2. С. 29-34.

8. ГОСТ Р ИСО 9001-2015. Национальный стандарт Российской Федерации. Системы менеджмента качества. Требования. Доступно по: https://base.garant.ru/71283056/. Ссылка активна на 10 апреля 2020.

\section{References}

1. Zakirova ASh, Akhmetzyanova GZ, Al'mukhametov AA. Ispol'zovaniye «berezhlivykh tekhnologiy» v okazanii ambulatorno-poliklinicheskoy pomoshchi. In: Pervichnaya mediko-sanitarnaya pomoshch'. Opyt peredovykh praktik $v$ ramkakh realizatsii natsional'nogo proyekta «Zdravookhraneniye»: sbornik materialov Respublikanskoy nauchno-prakticheskoy konferentsii; 6 Dec 2019; Kazan'. Kazan': Izd-vo KGMU; 2019. P. 55-7. (In Russ).

2. Gurianova VA, Ricker DD, Shubin LL. Condition of outpatient and polyclinic help for population in the Udmurt Republic in 2013. Sinergiya Nauk. 2019;(41):233-41. (In Russ).

3. Ruina OV, Zemskova SE, Luzina EA, et al.
Izmeneniya $\mathrm{v}$ rabote ambulatorno-poliklinicheskogo zvena; chto novogo? Nereshennyye voprosy. In: Meditsinskiy rabotnik goda - 2019: sbornik statey Mezhdunarodnogo nauchno-issledovatel'skogo konkursa; 25 Dec 2019; Petrozavodsk. Kazan'; 2019. P. 6-16. (In Russ).

4. Moskvina S, Cherepanova N. Kak reshit' problemu defitsita medpersonala. Opyt praktikov. Glavnaya Meditsinskaya Sestra. 2020;(4):48-51. (In Russ).

5. Borisova EA. Organization of the out-patient and policlinic help to the population of the city district «City of Yakutsk». Far East Medical Journal. 2018;(3):50-3. (In Russ).

6. Borisova EA, Savina NV, Lutskan IP, et al. New effective approaches in compensation of health workers. RUDN Journal of Medicine. 2015;(1):1221. (In Russ).

7. Borisova EA, Savvina NV, Lutskan IP, et al. The implementation of «effective contract» exemplified by the medical center of Yakutsk. Problems of Social Hygiene, Public Health and History of Medicine. 2015;23(2):29-34. (In Russ).

8. GOST R ISO 9001-2015. National standard of the Russian Federation. Quality management systems. Requirements. Available at: https://base.garant.ru/ 71283056/. Accessed: 2020 April 10.

\section{Информация об авторах [Authors Info]}

Борисова Елена Афраимовна - к.м.н., доцент кафедры общественного здоровья и здравоохранения, общей гигиены и биоэтики, СевероВосточный федеральный университет имени М.К. Аммосова, Якутск, Российская Федерация. SPIN: 3201-8577, ORCID ID: 0000-0001-6759-9183.

Elena A. Borisova - MD, PhD, Associate Professor of the Department of Public Health and Healthcare, General Hygiene and Bioethics, Ammosoy North-East Federal University, Yakutsk, Russian Federation. SPIN: 3201-8577, ORCID ID: 0000-0001-6759-9183.

*Луцкан Иван Петрович - к.м.н., доц., доцент кафедры общественного здоровья и здравоохранения, общей гигиены и биоэтики, СевероВосточный федеральный университет имени М.К. Аммосова, Якутск, Российская Федерация. E-mail: lutskan@mail.ru SPIN: 8222-3209, ORCID ID: 0000-0003-3440-1534.

Ivan P. Lutskan - MD, PhD, Associate Professor of the Department of Public Health and Healthcare, General Hygiene and Bioethics, Ammosov North-East Federal University, Yakutsk, Russian Federation. E-mail: lutskan@mail.ru SPIN: 8222-3209, ORCID ID: 0000-0003-3440-1534.

Саввина Надежда Валерьевна - д.м.н., проф., зав. кафедрой общественного здоровья и здравоохранения, общей гигиены и биоэтики, Северо-Восточный федеральный университет имени М.К. Аммосова, Якутск, Российская Федерация. SPIN: 3917-3282, ORCID ID: 0000-0003-2441-6193.

Nadezhda V. Savvina - MD, PhD, Professor, Head of the Department of Public Health and Healthcare, General Hygiene and Bioethics, Ammosov North-East Federal University, Yakutsk, Russian Federation.

SPIN: 3917-3282, ORCID ID: 0000-0003-2441-6193.

Тимофеев Леонид Федорович - д.м.н., профессор кафедры общественного здоровья и здравоохранения, общей гигиены и биоэтики, Северо-Восточный федеральный университет имени М.К. Аммосова, Якутск, Российская Федерация. SPIN: 2322-0355, ORCID ID: 0000-0003-1949-3504

Leonid F. Timofeev - MD, PhD, Professor of the Department of Public Health and Healthcare, General Hygiene and Bioethics, Ammosov NorthEast Federal University, Yakutsk, Russian Federation. SPIN: 2322-0355, ORCID ID: 0000-0003-1949-3504

Тимофеев Артем Леонидович - аспирант кафедры общественного здоровья и здравоохранения, общей гигиены и биоэтики, СевероВосточный федеральный университет имени М.К. Аммосова, Якутск, Российская Федерация.

SPIN: 7446-9806, ORCID ID: 0000-0003-1046-8064.

Artem L. Timofeev - PhD-Student of the Department of Public Health and Healthcare, General Hygiene and Bioethics, Ammosov North-East Federal University, Yakutsk, Russian Federation.

SPIN: 7446-9806, ORCID ID: 0000-0003-1046-8064 
Коновалов Олег Евгеньевич - д.м.н., проф., профессор кафедры общественного здоровья, здравоохранения и гигиены медицинского института, Российский университет дружбы народов; главный научный сотрудник, Национальный научно-исследовательский институт общественного здоровья имени Н.А. Семашко, Москва, Российская Федерация.

SPIN: 5181-8547, ORCID ID: 0000-0003-1974-9882.

Oleg E. Konovalov - MD, PhD, Professor, Professor of the Department of Public Health, Healthcare and Hygiene of the Medical Institute, Peoples' Friendship University of Russia; Chief Researcher, Semashko National Research Institute of Public Health, Moscow, Russian Federation. SPIN: 5181-8547, ORCID ID: 0000-0003-1974-9882.

Цитировать: Борисова Е.А., Луцкан И.П., Саввина Н.В., Тимофеев Л.Ф., Коновалов О.Е. Особенности организации амбулаторно-поликлинической помощи взрослому и детскому населению на базе медицинского центра г. Якутска Республики Саха (Якутия) // Наука молодых (Eruditio Juvenium). 2020. Т. 8, №4. С. 502-510. doi:10.23888/HMJ202084502-510

To cite this article: Borisova EA, Lutskan IP, Savvina NV, Timofeev LF, Konovalov OE. Peculiarities of organization of outpatient care for adults and children on base of medical center of Yakutsk city of the Republic of Sakha (Yakutia). Science of the young (Eruditio Juvenium). 2020;8(4):50210. doi:10.23888/HMJ202084502-510

Поступила / Received: 10.04 .2020

Принята в печать / Accepted: 01.12.2020 